Abstracta Iranica Abstracta Iranica

Revue bibliographique pour le domaine irano-aryen

Volume 42-43 | 2021

Comptes rendus des publications de 2019-2020

\title{
Pier Giorgio Borbone. History of Mar Yahballaha and Rabban Sauma: Edited, Translated, and Annotated
}

\section{Florence Jullien}

\section{(2) OpenEdition}

\section{Journals}

\section{Édition électronique}

URL : https://journals.openedition.org/abstractairanica/54191

DOI : 10.4000/abstractairanica.54191

ISSN : 1961-960X

Éditeur :

CNRS (UMR 7528 Mondes iraniens et indiens), Éditions de l'IFRI

Référence électronique

Florence Jullien, « Pier Giorgio Borbone. History of Mar Yahballaha and Rabban Sauma: Edited, Translated, and Annotated », Abstracta Iranica [En ligne], Volume 42-43 | 2021, document 31, mis en ligne le 30 décembre 2021, consulté le 13 décembre 2022. URL : http://journals.openedition.org/ abstractairanica/54191 ; DOI : https://doi.org/10.4000/abstractairanica.54191

Ce document a été généré automatiquement le 13 décembre 2022.

Tous droits réservés 
Pier Giorgio Borbone. History of Mar Yahballaha and Rabban Sauma: Edited, Translated, and Annotated

Florence Jullien 


\section{RÉFÉRENCE}

Pier Giorgio Borbone. History of Mar Yahballaha and Rabban Sauma: Edited, Translated, and Annotated. Translated from the Italian by Laura E. Parodi. Hambourg : Tredition, 2020, 424 p., ISBN: 978-3-7497-1296-0 ; 978-3-7497-1298-4 (eBook).

Ce récit retrace l'itinéraire de deux moines syro-orientaux partis depuis la Chine vers l'Iran en 1274 ; l'un d'eux, Marc, sera élu patriarche de l'Église d'Orient sous le nom de Yahballaha [III], et le second, Rabban Sauma, sera choisi comme émissaire auprès du pape et des tribunaux de France et d'Angleterre par l'Ilkhan mongol Arghun. Le texte était connu depuis 1893 et 1894 grâce à la traduction pionnière effectuée par J.-B. Chabot dans la Revue de l'Orient latin (p. 566-610; p. 73-143, p. 235-300). L'ouvrage constitue la traduction anglaise entièrement révisée d'une édition antérieure publiée en français (trad. Egly Alexandre à l'Harmattan) en 2008, puis en italien en $2010 \mathrm{chez}$ Lulu Press, Moncalieri. La traduction anglaise a été soigneusement revue sur le syriaque et le texte syriaque lui-même est présenté dans une nouvelle édition, basée sur une collation de tous les manuscrits existants. L. Parodi effectue plusieurs suggestions améliorant la version italienne originale. Des enrichissements conséquents sont par ailleurs apportés au commentaire historique par l'A., tenant compte des nombreux travaux parus depuis sur l'Empire mongol. La bibliographie a été également entièrement remise à jour. Emanuela Braida présente sa traduction en anglais de la Vita en arabe de Mār Yahballaha ("Life of Mar Yahballaha from the Arabic Chronicle of the Patriarchs of the Church of the East”, p. 339-343). L'ouvrage fait désormais référence et le public anglophone trouvera là une excellente édition commentée.

\section{AUTEURS}

\section{FLORENCE JULLIEN}

CNRS, CeRMI, Paris 